\title{
Anti-corrosive effect of Cassia alata leaves extract on \\ Mild steel in 1.0N Hydrochloric acid
}

A. Petchiammal, P.Deepa Rani, S.Seetha lakshmi and S.Selvaraj.

Post graduate and Research Department of chemistry,

Sri Paramakalyani College, Alwarkurichi-627412, Tamil Nadu, India.

Mail id: ap_mscchem@yahoo.in

Phone No. 9442064252

Fax no: 04634-283530.

\section{ABSTRACT}

The inhibition effect of Cassia alata leaves extract on corrosion of mild steel in $1 \mathrm{~N} \mathrm{HCl}$ was investigated through mass loss measurements with various time and temperature. The observed result indicated that the corrosion inhibition efficiency and degree of surface coverage were increased with increase of inhibitor concentration and temperature. The thermodynamic parameters $\left(\mathrm{E}_{\mathrm{a}}, \Delta \mathrm{H}_{\mathrm{ads}}, \Delta \mathrm{G}_{\mathrm{ads}}, \Delta \mathrm{S}_{\mathrm{ads}}\right)$ were evaluated for corrosion inhibition process which suggests that the adsorption is endothermic, spontaneous and chemisorptions and also the inhibitor follows Langmuir adsorption isotherm. The protective film formed on metal surface was analyzed using spectroscopic studies viz, UV, FT-IR and EDX techniques.

KEYWORDS: Mild steel, Corrosion, Cassia alata leaves, Mass loss, Adsorption isotherm

\section{Council for Innovative Research}

Peer Review Research Publishing System

Journal: Journal of Advances in Chemistry

Vol 2, No. 2

editor@cirworld.com

www.cirworld.com, member.cirworld.com 


\section{INTRODUCTION}

Mild steel is the material of choice almost all the field in Worldwide due to its low cost and easy availability. It has been extensively used under different condition in chemical and allied industries in handling alkaline, acid and salt solution. Chloride, sulphate and nitrate ions in aqueous media are particularly aggressive and accelerate the corrosion. One of the best way of protecting mild steel from corrosion is the use of inhibitors [1]. But the use of chemical inhibitor has been found to be more expensive, toxic, non bio-degradable and harmful to living things. Hence there is a big problem for researchers to search the non-toxic, eco-friendly corrosion inhibitors. Recent years, several green inhibitors have been used for the prevention of corrosion by most of the investigators. Few examples are Allium Cepa [2], Eucalyptus globulus [3], Phyllanthus amarus [4], bitter leaf powder [5], Carob seed oil [6], Bacopa monnieri [7], Citrullus Vulgaris peel [8], Albizia lebbeck seed [9], Hibiscus Esculenta leaves [10], Jatropha curcas [11], Eugenia Jambolana [12]. In continuous of our research work, our present investigation is an anti-corrosive effect of Cassia alata leaves on mild steel in $1 \mathrm{~N}$ Hydrochloric acid have been investigated with various period of contact and temperature using the mass loss measurements and the corrosion product on metal surface is analysed by UV, FT-IR, EDX spectral studies.

\section{EXPERIMENTAL}

\section{Specimen preparation}

Mild steel specimen were mechanically pressed to cut different coupons, each of dimension exactly $20 \mathrm{~cm}^{2}(5 \times 2 \times 2 \mathrm{~cm})$, polished with emery wheel of 80 and 120, and degreased with trichloroethylene, then washed with distilled water cleaned, dried and then stored in desiccator and used throughout our present study.

\section{Preparation of Cassia alata leaves (CAL) extract}

Freshly available Cassia alata leaves were dried well, grinded and soaked in required alcohol for about $48 \mathrm{hrs}$, and then filtered, followed by evaporation in order to remove the excess of alcohol completely and the pure plant alcoholic extract was collected. From this extract the different concentration $(0-1000 \mathrm{ppm})$ of stock solution was prepared and used throughout the present investigation.

\section{Mass loss measurement}

In mass loss measurement, the specimen of mild steel is immersed exactly in $100 \mathrm{ml}$ of the test solution in the presence and absence of the inhibitor. The specimens were withdrawn from the test solutions after 24 to $360 \mathrm{hrs}$ at room temperature and one hour at the temperature range of $303 \mathrm{~K}$ to $323 \mathrm{~K}$. From this observed data, the corrosion rate ( $\mathrm{mmpy}$ ), percentage of inhibition efficiency (\%l.E) and surface coverage $(\theta)$ was calculated using the following formulae (1-3).

$$
\text { Corrosion Rate mmpy }=\frac{87.6 \times \mathrm{W}}{\mathrm{DAT}}
$$

Where, $\mathrm{mmpy}=$ millimeter per year, $\mathrm{W}=$ Mass loss $(\mathrm{mg}), \mathrm{D}=$ Density $\left(\mathrm{gm} / \mathrm{cm}^{3}\right), A=$ Area of specimen $\left(\mathrm{cm}^{2}\right), T=\operatorname{time~in~}$ hours.

$$
\begin{gathered}
\% \mathrm{IE}=\frac{\mathrm{W}_{1}-\mathrm{W}_{2}}{\mathrm{~W}_{1}} \times 100 \\
\theta=\frac{\mathrm{W}_{1}-\mathrm{W}_{2}}{\mathrm{~W}_{1}}
\end{gathered}
$$

Where $W_{1}$ and $W_{2}$ are the corrosion rates in the absence and presence of the inhibitor respectively.

\section{SURFACE CHARACTERIZATION}

The predominant elements present in the corrosion products was recorded by an EDX detector using a model Oxford Instrument Model - INCA Penta xFET. The stretching frequency of functional groups in the corrosion product was analysed by FT-IR spectrum using the model Jasco/Japan. The absorption maximum of the corrosion product was analysed by UV spectra using the Model Jasco V670.

\section{RESULTS AND DISCUSSION}

Table 1 reflects that the variation of corrosion parameters with concentration of CAL extract on mild steel at different period of contact in $1 \mathrm{~N}$ Hydrochloric acid. It revealed that the corrosion rate was decreased gradually with the addition of inhibitor. The maximum of $73.62 \%$ inhibition efficiency was achieved at 1000 ppm of inhibitor concentration after 360 hrs exposure time. The almost greater than $73 \%$ of surface coverage $(\theta)$ was achieved due to the co-ordination between the mild steel metal and the hetero atom (oxygen, nitrogen) present in the inhibitor. 
Table 1: Variation of corrosion parameters with Concentration of CAL extract on mild steel at different period of contact in $1 \mathrm{~N}$ Hydrochloric acid

\begin{tabular}{|c|c|c|c|c|c|c|c|c|c|c|c|c|}
\hline $\begin{array}{c}\text { Conc. of } \\
\text { inhibitor } \\
(\mathrm{ppm})\end{array}$ & \multicolumn{2}{|c|}{$24 \mathrm{hrs}$} & \multicolumn{2}{|c|}{$72 \mathrm{hrs}$} & \multicolumn{2}{c|}{$120 \mathrm{hrs}$} & \multicolumn{2}{c|}{$168 \mathrm{hrs}$} & \multicolumn{2}{c|}{$216 \mathrm{hrs}$} & \multicolumn{2}{c|}{$360 \mathrm{hrs}$} \\
\cline { 2 - 14 } & C.R & $\%$ l.E & C.R & $\%$ l.E & C.R & $\%$ I.E & C.R & $\%$ l.E & C.R & $\%$ I.E & C.R & $\%$ l.E \\
\hline 0 & 5.3635 & ---- & 3.1113 & --- & 2.3405 & --- & 2.2987 & ---- & 2.1615 & --- & 2.0123 & --- \\
\hline 10 & 4.1097 & 23.3 & 2.3451 & 24.6 & 1.5185 & 35.1 & 1.2804 & 44.2 & 0.9668 & 55.2 & 0.6780 & 66.3 \\
\hline 50 & 3.7615 & 34.9 & 2.2445 & 27.8 & 1.4674 & 37.3 & 1.2074 & 47.4 & 0.8422 & 61.0 & 0.5960 & 70.3 \\
\hline 100 & 3.5989 & 32.9 & 1.8575 & 40.3 & 1.4489 & 38.0 & 1.1278 & 50.9 & 0.7809 & 63.8 & 0.5789 & 71.2 \\
\hline 500 & 3.4828 & 35.0 & 1.6718 & 46.2 & 1.4135 & 39.6 & 1.1046 & 51.9 & 0.7493 & 65.3 & 0.5665 & 71.8 \\
\hline 1000 & 3.3203 & 38.0 & 1.1919 & 61.6 & 1.3560 & 42.0 & 1.0348 & 54.9 & 0.7367 & 65.9 & 0.5309 & 73.6 \\
\hline
\end{tabular}

Variation of corrosion parameters with various concentration of CAL extract on mild steel at different temperature in $1 \mathrm{~N}$ Hydrochloric acid is shown in Table-2. As can be seen from Table-2 that the corrosion rate was decreased and the percentage of inhibition efficiency increased with increase of inhibitor concentration with rise in temperature from 303 to $323 \mathrm{~K}$. It suggested that the adsorbed layer retards the corrosion rate when rise in temperature from 303 to $323 \mathrm{~K}$. The maximum of $75.00 \%$ inhibition efficiency was achieved at $323 \mathrm{~K}$. The value of inhibition efficiency was increased with rise in temperature. Thus, the inhibitor efficiencies were temperature dependent and it being chemically adsorbed at all temperatures. This was due to the adsorption of active molecules on the metal surface is higher than the desorption process.

Table 2: Variation of corrosion parameters with Concentration of CAL extract on mild steel at different temperature in $1 \mathrm{~N}$ Hydrochloric acid

\begin{tabular}{|c|c|c|c|c|}
\hline $\begin{array}{c}\text { Temperature } \\
\text { (K) }\end{array}$ & $\begin{array}{c}\text { Concentration } \\
\text { of inhibitor } \\
\text { (ppm) }\end{array}$ & $\begin{array}{c}\text { Mass loss } \\
(\mathrm{mg})\end{array}$ & $\begin{array}{c}\text { Corrosion } \\
\text { rate (mmpy) }\end{array}$ & $\begin{array}{c}\text { Inhibition } \\
\text { efficiency } \\
\text { (\%) }\end{array}$ \\
\hline \multirow{6}{*}{303} & 0 & 372 & 207.29 & -- \\
\hline & 10 & 211 & 117.58 & 43.27 \\
\hline & 50 & 200 & 111.45 & 46.23 \\
\hline & 100 & 183 & 101.97 & 50.80 \\
\hline & 500 & 147 & 081.92 & 60.48 \\
\hline & 1000 & 135 & 075.23 & 63.70 \\
\hline \multirow{6}{*}{313} & 0 & 502 & 279.74 & --- \\
\hline & 10 & 289 & 161.04 & 42.43 \\
\hline & 50 & 200 & 111.45 & 60.15 \\
\hline & 100 & 187 & 104.20 & 62.74 \\
\hline & 500 & 175 & 097.52 & 65.13 \\
\hline & 1000 & 152 & 084.70 & 69.72 \\
\hline \multirow{6}{*}{323} & 0 & 572 & 318.74 & ---- \\
\hline & 10 & 298 & 166.06 & 47.90 \\
\hline & 50 & 208 & 115.90 & 63.63 \\
\hline & 100 & 198 & 110.33 & 65.38 \\
\hline & 500 & 147 & 094.73 & 70.27 \\
\hline & 1000 & 135 & 079.68 & 75.00 \\
\hline
\end{tabular}




\section{Adsorption isotherm}

The adsorption process was influenced by the chemical structures of molecule present in CAL, the distribution of charge in molecule, the nature and surface charge of metal and the type of aggressive media. The surface coverage values $(\theta)$ were tested graphically for fitting a suitable adsorption isotherm. In those cases, the plot of $\log C$ versus log $\mathrm{C} / \theta$ yield a straight line, clearly proving that the adsorption of the used inhibitors from $1 \mathrm{~N} \mathrm{HCl}$ solutions on the metal surface obeys the Langmuir adsorption isotherm (Fig.1) which is represented by equation (7).

$$
\log \mathrm{C} / \theta=\log \mathrm{C}-\log \mathrm{K}
$$

Where $\theta$ is the degree of surface coverage, $\mathrm{C}$ is the concentration of the inhibitor solution and $\mathrm{K}$ is the equilibrium constant from which the free energy of adsorption $\left(\Delta G_{a d s}\right)$ is calculated by the following Equation (8) and the corresponding values are shown in Table-2. The negative values of $\Delta G_{\text {ads }}$ suggested that the adsorption of CAL extract onto the metal surface is a spontaneous process and the adsorbed layer is more stable.

$$
\Delta \mathrm{G}_{\text {ads }}=-2.303 \mathrm{RT} \log (55.5 \mathrm{~K})
$$

Where $R$ is the gas constant, $T$ is the temperature. The above adsorption isotherm reveals that there is no interaction between the adsorbate and adsorbent

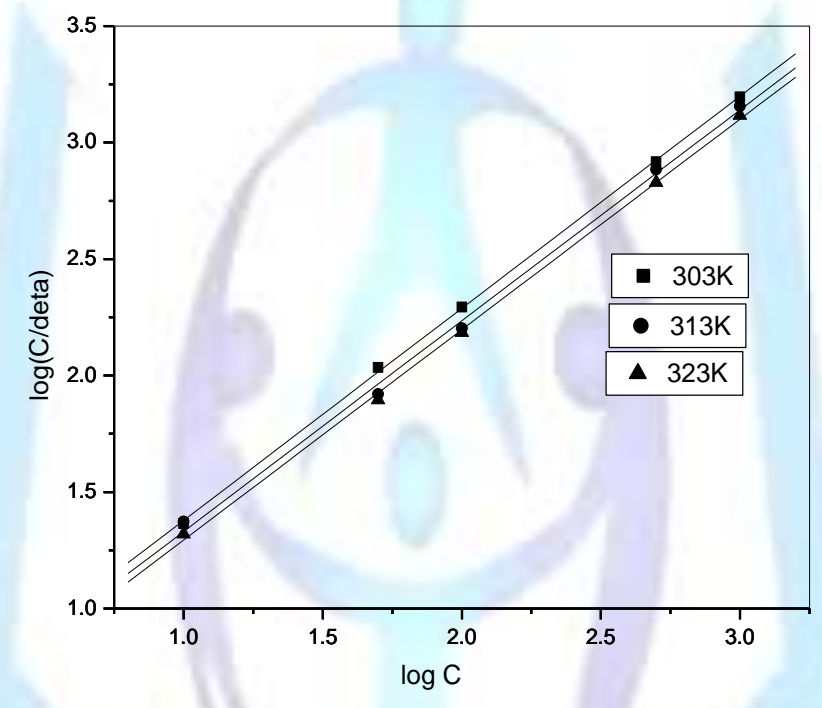

Figure 1 Langmuir isotherm for the adsorption of CAL inhibitor on mild steel in $1 \mathrm{~N}$ Hydrochloric acid.

Table 3: Langmuir adsorption parameters for the adsorption of CAL extract on Mild steel in 1N Hydrochloric acid

\begin{tabular}{|c|c|c|}
\hline $\begin{array}{c}\text { Adsorption } \\
\text { Isotherms }\end{array}$ & $\begin{array}{c}\text { Temperature } \\
\text { (Kelvin) }\end{array}$ & $\begin{array}{c}\Delta \mathrm{G}_{\text {ads }} \\
\mathrm{kJ} / \mathrm{mol}\end{array}$ \\
\hline \multirow{2}{*}{ Langmuir } & 303 & -1.914 \\
\cline { 2 - 3 } & 313 & -2.222 \\
\cline { 2 - 3 } & 323 & -2.522 \\
\hline
\end{tabular}

\section{Thermodynamics parameters}

A plot of log CR vs. 1000/T gave straight lines as shown in Fig.2. The apparent activation energy (Ea) was calculated by using following relationship.

$$
\begin{gathered}
C R=A \exp \left(-E_{a} / R T\right) \\
\log C R=\log A-E_{a} / R T
\end{gathered}
$$

Where $\mathrm{Ea}$ is the apparent activation energy for the corrosion of mild steel in $1 \mathrm{~N} \mathrm{HCl}$ solution, $\mathrm{R}$ the gas constant, $\mathrm{A}$ the Arrhenius pre-exponential factor and $\mathrm{T}$ is the absolute temperature. The values of Ea obtained from the slope of the lines are given in Table-4 


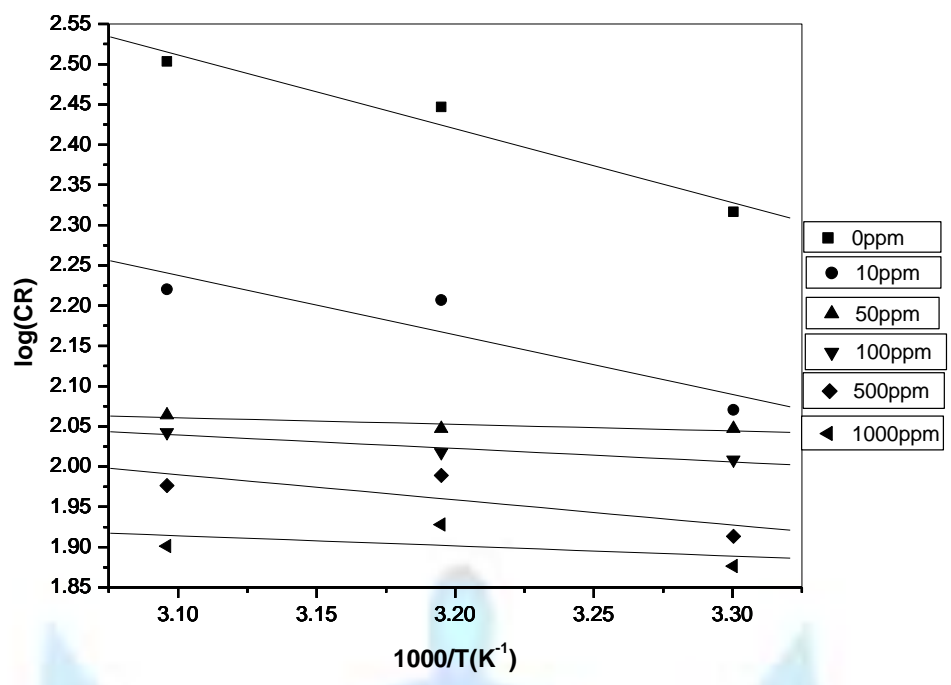

Figure 2 Arrhenius plots of mild steel in acid with and without different concentrations of CAL

An alternative formula of the Arrhenius equation is the transition state equation

$$
C R=R T / N h \exp (\Delta S / R) \exp (-\Delta H / R T)
$$

where $\mathrm{h}$ is the Planck's constant, $\mathrm{N}$ the Avogadro's number, $\Delta S$ the entropy of activation, and $\Delta \mathrm{H}$ the enthalpy of activation. A plot of $\log (C R / T)$ vs. 1000/T should give a straight line (Fig.3) with a slope of $(-\Delta H / R)$ and an intercept of $[\log (R / N h))+(\Delta S / R)]$, from which the values of $\Delta S$ and $\Delta H$ were calculated and listed in Table-4. The data shows that the thermodynamic parameters (Ea and $\Delta \mathrm{H}$ ) of the corrosion of mild steel in $1 \mathrm{~N} \mathrm{HCl}$ solution in the presence of the inhibitors are lower than those in the free acid solution indicating less energy barrier for the reaction in the presence of the inhibitor is attained. The positive value of enthalpy of activation reflects the endothermic nature of metal dissolution process meaning that dissolution of metal is difficult. The increase of $\Delta S$ is generally interpreted by increase in disorder taking place on going from reactants to the activated complex [13]

Table 4: Thermodynamic parameters for mild steel in $1 \mathrm{~N} \mathrm{HCl}$ solution obtained from weight loss measurements.

\begin{tabular}{|c|c|c|c|c|}
\hline S.No & $\begin{array}{c}\text { Concentration } \\
\text { of CAL }(\mathrm{ppm})\end{array}$ & $\begin{array}{c}\mathrm{Ea} \\
(\mathrm{kJ} \mathrm{mol}-1)\end{array}$ & $\begin{array}{c}\Delta \mathrm{H}(\mathrm{kJ} \\
\mathrm{mol}-1)\end{array}$ & $\begin{array}{c}\Delta \mathrm{S}(\mathrm{J} \mathrm{K}-1 \\
\mathrm{mol}-1)\end{array}$ \\
\hline 1 & 0 & 7.63142 & 6.5022 & 8.5795 \\
\hline 2 & 10 & 6.15111 & 5.0219 & 9.4771 \\
\hline 3 & 50 & 0.68416 & 0.4450 & 11.8856 \\
\hline 5 & 100 & 1.38511 & 0.2559 & 11.6249 \\
\hline 6 & 500 & 2.60444 & 1.4752 & 11.1840 \\
\hline
\end{tabular}




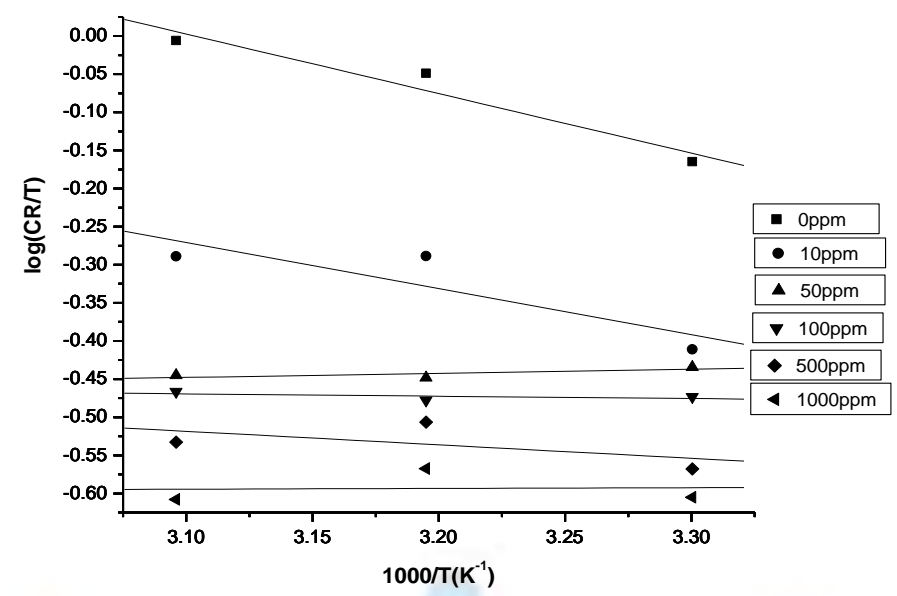

Figure 3 The relation between $\log (C R / T)$ and 1/T for different concentrations of CAL extract

\section{MORPHOLOGY EXAMINATION OF MILD STEEL}

\section{UV spectrum:}

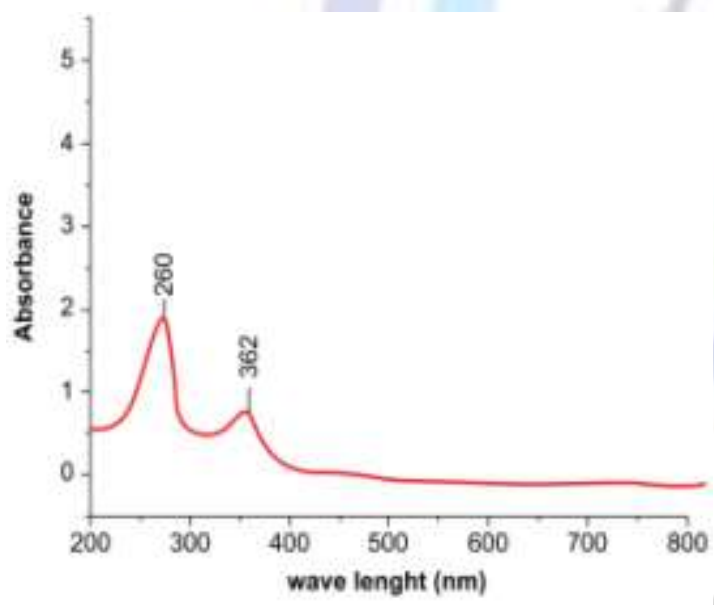

(a)

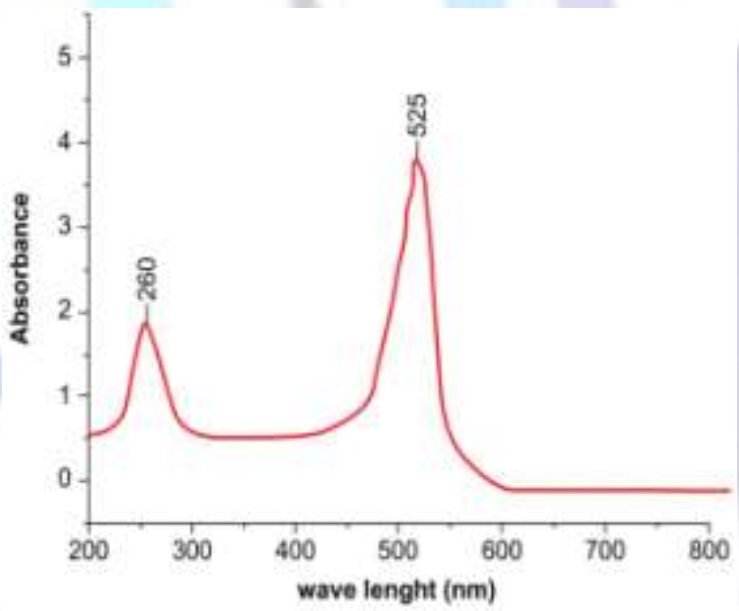

(b)

Figure 4 UV spectrum of ethanolic extract of CAL (a), the corrosion product on mild steel in $1 \mathrm{~N} \mathrm{HCl}$ in the presence of CAL extract (b).

Fig.4(a) and (b) shows that the UV visible spectrum of ethanolic extract of CAL and the corrosion product on the surface of Mild steel in the presence of CAL extract in $1 \mathrm{~N}$ Hydrochloric acid respectively. In the UV spectrum, the two absorption bands around 260 and $362 \mathrm{~nm}$ and bands around 260 and 525nm were noticed in Fig.4(a) and (b) respectively. In the presence of inhibitor one band $(260 \mathrm{~nm})$ remains unchanged and another band $(362 \mathrm{~nm})$ shifted to higher wavelength region. The change of absorption band from the above may confirmed the strong co-ordination between the active group present in the inhibitor molecules and the metal surface.

\section{FT-IR analysis}

The Fig.5 and 6 reflects that the FT-IR spectrum of the ethanolic extract of CAL inhibitor and the corrosion product on mild steel in the presence of inhibitor in $1 \mathrm{~N}$ Hydrochloric acid. On comparing these spectra, the prominent peak is shifted from 3317.34 to $3355.88 \mathrm{~cm}^{-1}$ for $-\mathrm{OH}$ group, the frequency at $1119.93 \mathrm{~cm}^{-1}$ is attributed to $-\mathrm{C}-\mathrm{N}$ stretching in amine is shifted to $1149.38 \mathrm{~cm}^{-1}$ indicates that the binding between metal and inhibitor takes place through amino group. Thus the FT-IR spectra support the fact that the corrosion inhibition of CAL inhibitor on mild steel in $1 \mathrm{~N}$ Hydrochloric acid may be the adsorption of active molecule in the inhibitor and surface of the metal. 


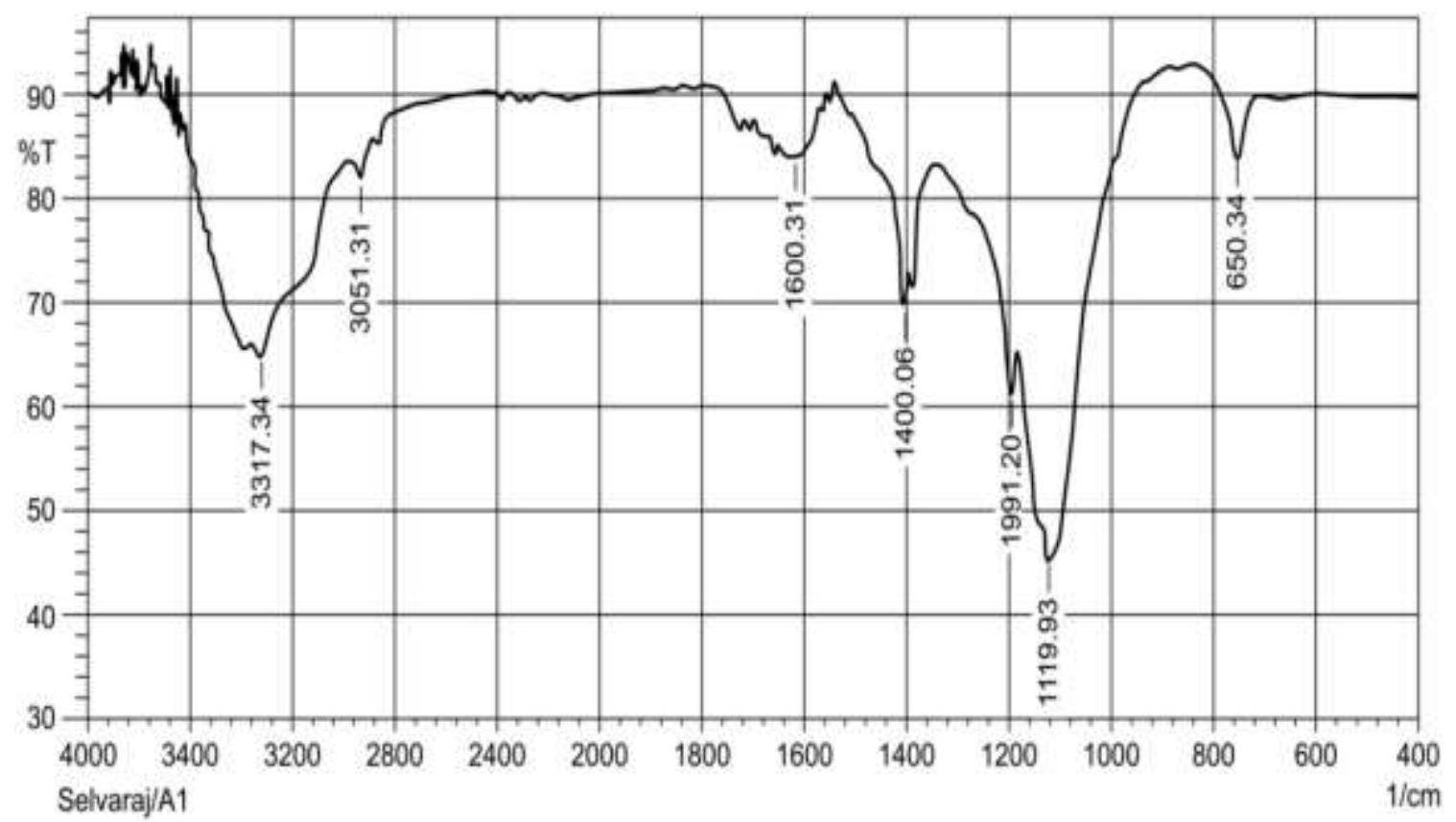

Figure 5 FT-IR spectrum of ethanolic extact of Cassia Alata leaves (CAL)

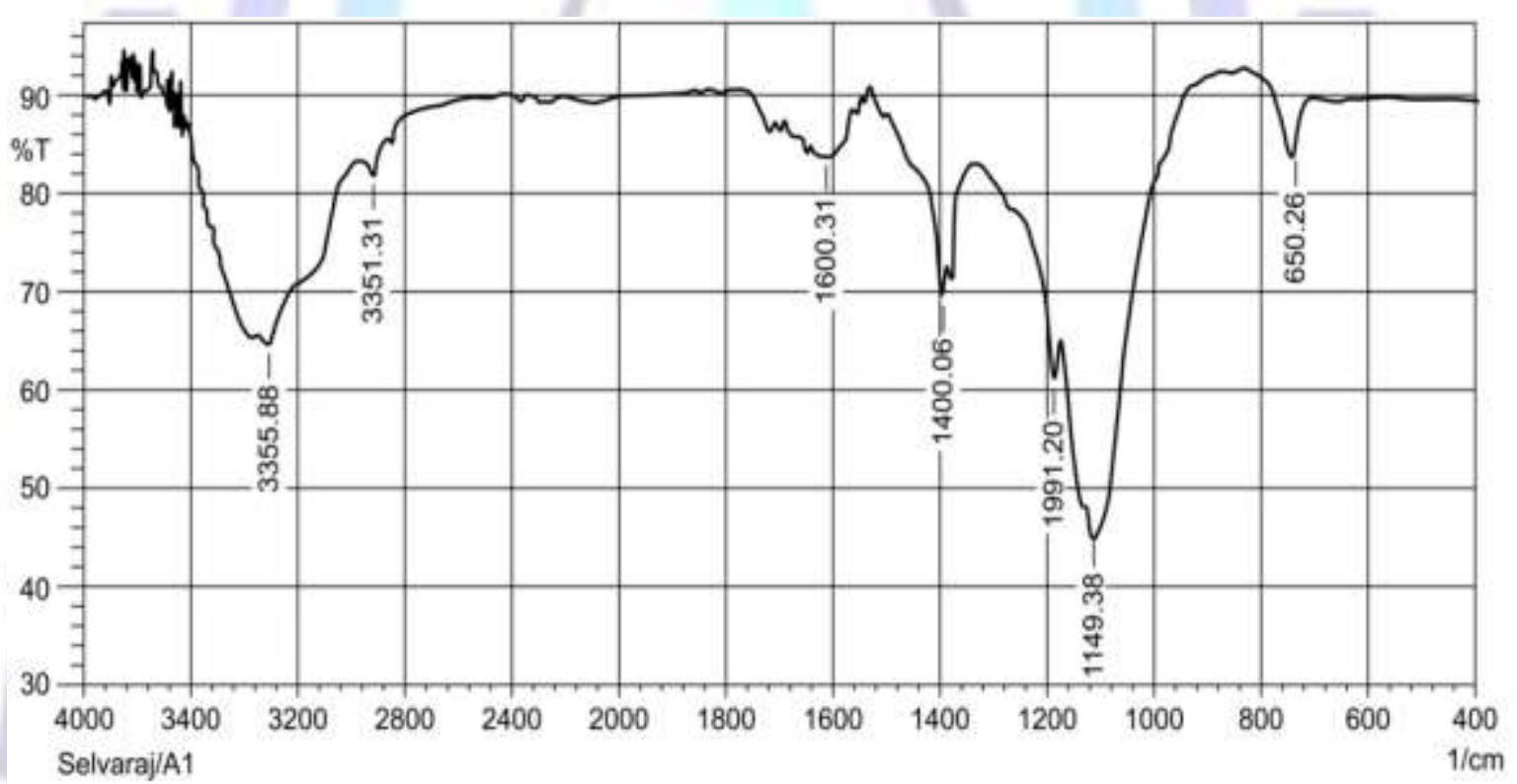

Figure 6 FT-IR spectrum for the corrosion product on mild steel in the presence of CAL extract with 1N Hydrochloric acid

\section{EDX spectrum}

EDX spectroscopy was used to determine the elements present on the mild steel surface in the absence and presence of inhibitor. Fig.7 and 8 represents the EDX spectra for the corrosion product on metal surface in the absence and presence of optimum concentrations of CAL extract in $1 \mathrm{~N}$ Hydrochloric acid. In the absence of inhibitor molecules, the spectrum may concluded that the existence of chlorine due to the formation of metal chloride and in addition to this, spectrum consists of iron, silicon, carbon which is the part of composition of mild steel. However, in the presence of the optimum concentrations of the inhibitors, nitrogen and oxygen atoms are found to be present in the corrosion product on the metal surface. It clearly indicates that these hetero atoms present in the inhibitor molecules may involve the complex formation with metal atom during the adsorption process and prevent the further dissolution of metal against corrosion. 


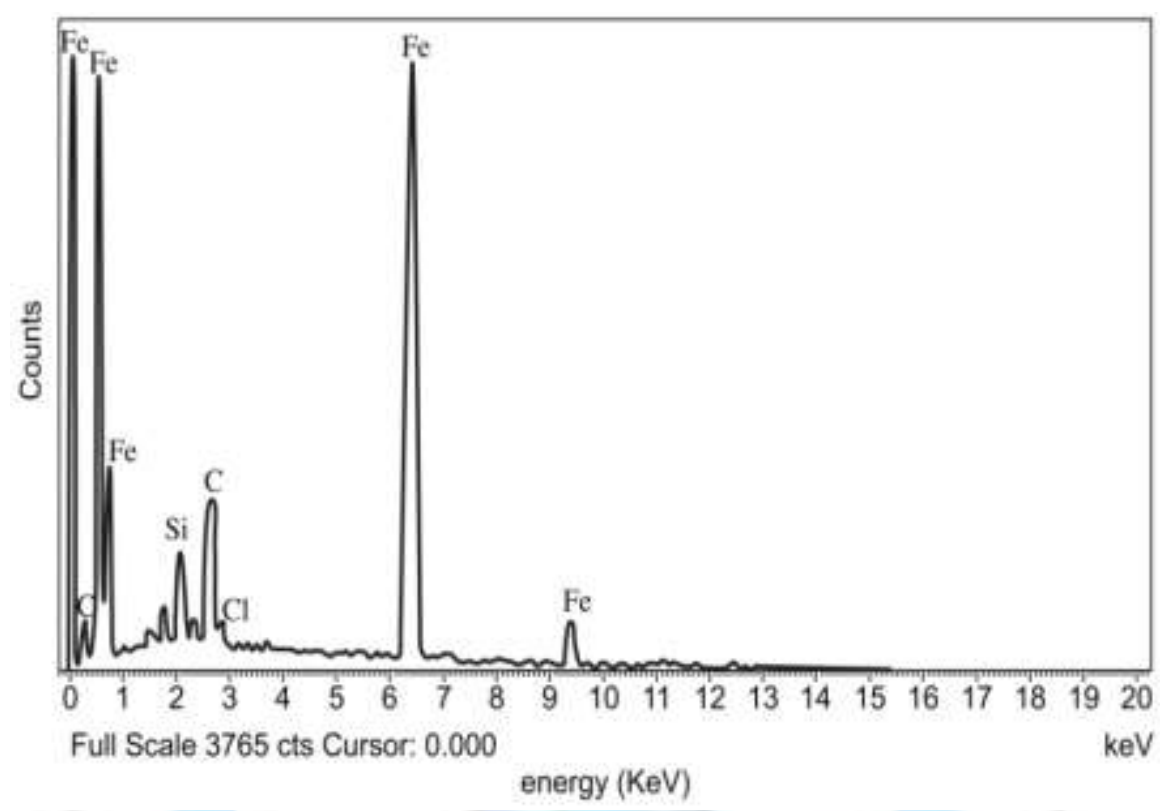

Figure 7 EDX spectrum of the corrosion product on mild steel surface in $1 \mathrm{~N} \mathrm{HCl}$

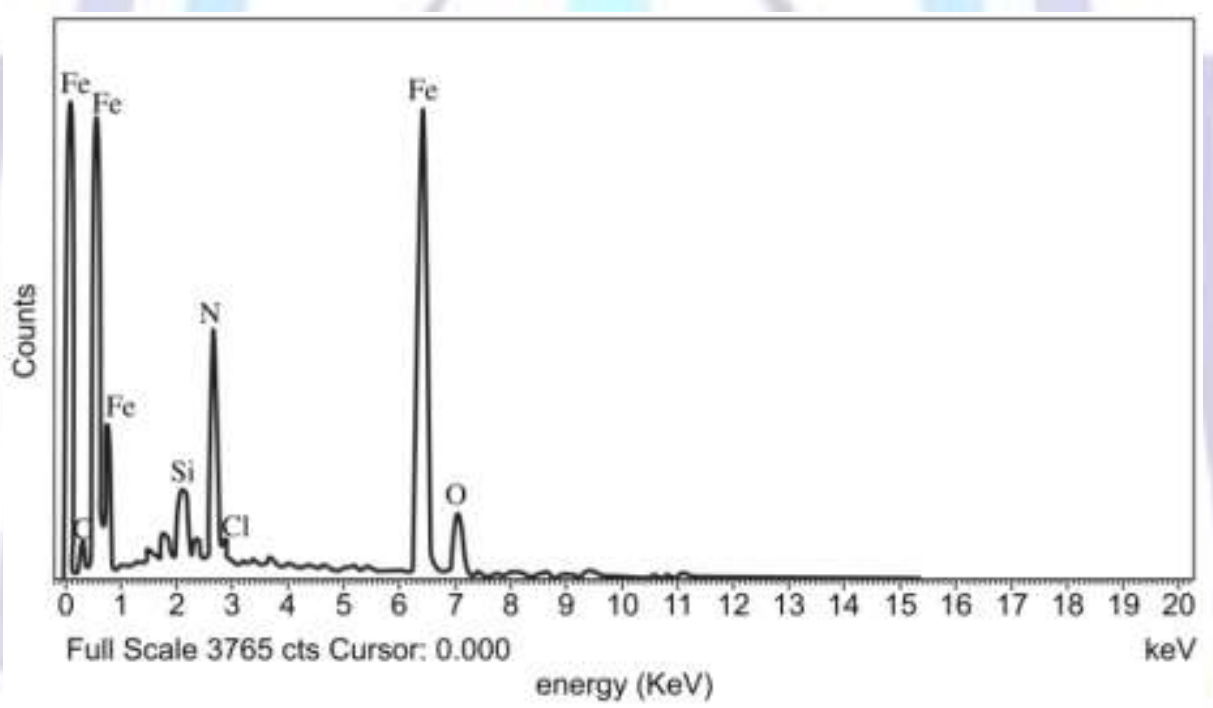

Figure 8 EDX spectrum of the corrosion product on mild steel in the presence of CAL extract in $1 \mathrm{~N} \mathrm{HCI}$

\section{CONCLUSION}

On the basis of the above results, it can be seen that Cassia alata leaves is a good inhibitor for mild steel in $1 \mathrm{~N} \mathrm{HCl}$. The inhibition efficiency of CAL attains a maximum value of $73.62 \%$. This inhibition effect increases with the increase of inhibitor concentration. The inhibition efficiency of CAL is dependent on temperature. CAL shows an adsorption on the metal surface according to the Langmuir adsorption isotherm model. The value of activation energy $\left(E_{a}\right)$, enthalpy of adsorption $\left(\Delta \mathrm{H}_{\mathrm{ads}}\right)$ and free energy changes $\left(\Delta \mathrm{G}_{\mathrm{ads}}\right)$ indicates that the adsorption of inhibitor on metal surface follows chemical, endothermic and spontaneous process respectively. The corrosion product over the surface of mild steel is characterized by UV, FT-IR and EDX studies also confirm protective film completely shielded the entire metal surface and reduce the further dissolution of metal against corrosion.

\section{REFERENCE}

[1]. Anand B, Balasubramanian, V. 2011. Corrosion Behaviour of Mild Steel in Acidic Medium in Presence of Aqueous Extract of Allamanda Blanchetii, E-J.of Chem. 8, 226-230.

[2]. Sulaiman S, Nor-Anuar A, Abd-Razak A.S, Chelliapan S. 2012. A study of using Allium Cepa (onion) as natural corrosion inhibitor in industrial chill wastewater system, Res.j.chem.sci, 2, 10-16

[3]. Rekkab S. et.al, 2012. Green corrosion inhibitor from essential oil of Eucalyptus globulus (myrtaceae) for C38 steel in sulfuricacid solution, j. Mater. Environ. Sci, 3, 613-627. 
[4].Sribharathya V, Susai Rajendran and Sathiyabama, J. (2013). Inhibitory action of Phyllanthus amarus extracts on the corrosion 2-thiophene carboxaldehyde as corrosion inhibitor for zinc in phosphoric acid solution of mild steel in seawater, Chem. Sci Trans, 2, 315-321.

[5]. Ayeni F.A, et.al, (2012). Effect of aqueous extracts of bitter leaf powder on the corrosion inhibition of Al-Si alloy in 0.5 M caustic soda solution, Advanced Mater. Res, 367: 319-325.

[6]. Dris Ben Hmamou et.al, (2012). Carob seed oil: an efficient inhibitor of C38 steel corrosion in Hydrochloric acid, Inter. J. of Industrial Chem, 3:25

[7]. Ambrish Singh et.al, (2012). Stem extract of brahmi (Bacopa Monnieri) as green corrosion inhibitor for aluminum in $\mathrm{NaOH}$ solution, Int. J. Electrochem. Sci, 7: 3409 - 3419.

[8]. Petchiammal A, Deepa Rani P, Selvaraj S, and Kalirajan K 2012. Corrosion Protection of Zinc in Natural Sea Water using Citrullus Vulgaris peel as an Inhibitor, Res. J. of Chem. Sci, 2, 24-34.

[9]. Petchiammal A, Selvaraj S, and Kalirajan K. 2013. Albizia lebbeck seed extract as effective corrosion inhibitor for Mild steel in acid medium. Bio interface res. in App. Chem, 3, 498-506

[10]. Petchiammal A, Selvaraj S, and Kalirajan K. 2013. Influence of Hibiscus Esculenta leaves on the corrosion of stainless steel in acid medium, Inter. J. of Univ. Pharm. and Bio Sci, 2, 242-252

[11]. Deepa Rani P and Selvaraj S. 2011. Comparitive account of Jatropha curcas on Brass(Cu- 40Zn) in acid and Natural sea water environment, Pacific J. of Sci. and Technol, 12, 38- 49.

[12]. Deepa Rani P et al. 2013. Eugenia Jambolana Used as Corrosion Inhibitor on Mild Steel in $1 \mathrm{~N}$ Hydrochloric Acid Medium, 2, 215-225

[13]. Ayatia N.S et al. 2011. Inhibitive effect of synthesized 2-(3-pyridyl)-3,4-dihydro-4- quinazolinone as a corrosion inhibitor for mild steel in hydrochloric acid, Mater. Chem. and Phy, 126, 873-879

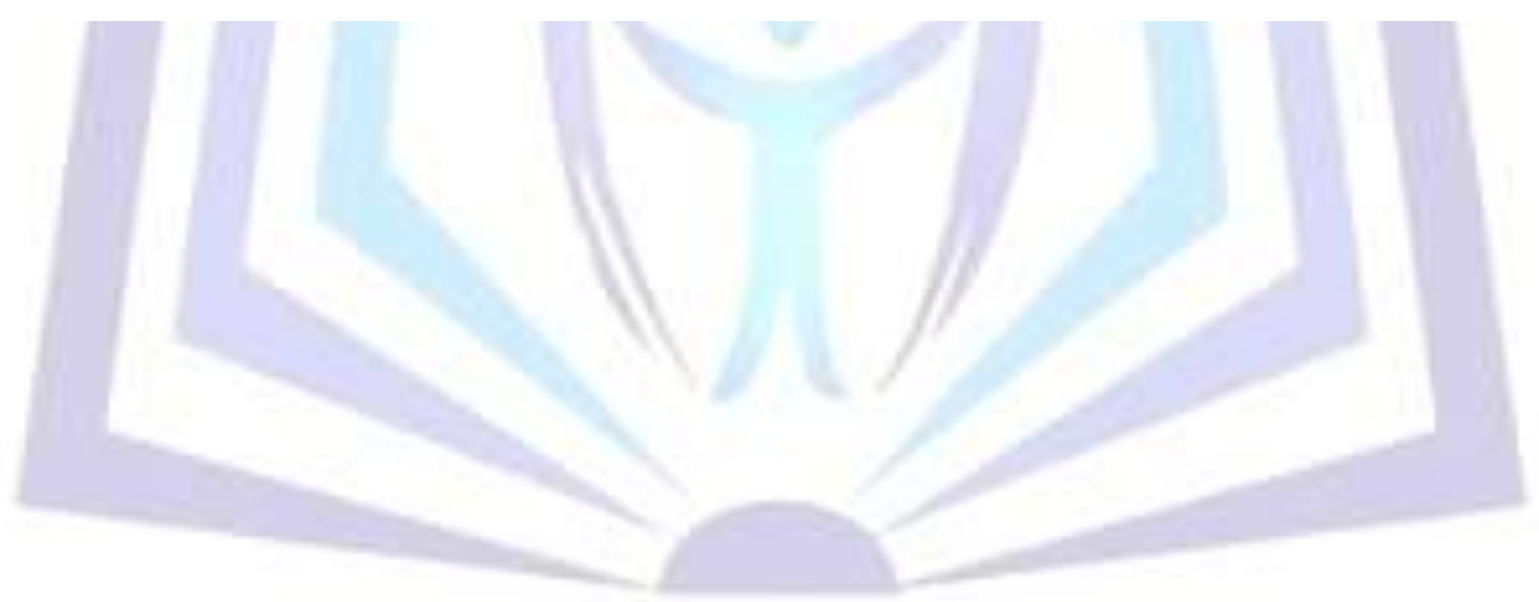

